\title{
CHARACTERISATION AND COMPARISON OF DIFFERENT SIZES NANO ZnO POWDERS
}

\author{
1,2Jiří ZEGZULKA, ${ }^{1}$ Lucie JEZERSKÁ, ${ }^{1}$ Martin ŽÍDEK, ${ }^{2}$ Rostislav PROKEŠ \\ ${ }^{1}$ VSB-Technical University of Ostrava, ENET Centre, Laboratory of Bulk Materials, Ostrava, \\ Czech Republic, EU, lucie.jezerska@vsb.cz \\ ${ }^{2}$ VSB-Technical University of Ostrava, Faculty of Mining and Geology, Department of Mining Engineering \\ and Safety, Ostrava, Czech Republic, EU
}

https://doi.org/10.37904/nanocon.2019.8606

\begin{abstract}
Zinc oxide plays an important role in various industries from electronics to cosmetics. Due to its special characteristics such as antiseptic, astringent and fungistatic properties, anti-corrosion, low electron conductivity and good heat resistance is still the subject of current research. Therefore, friction parameters, compressibility factors, flowability and sensitivity to aeration have been investigated. For this purpose, two nano and one micro-sized $\mathrm{ZnO}$ powders were characterized and compared. Experimental work was performed by the Powder Rheometer and Disk Centrifuge. Also a shape analysis of samples were made. The subjects were questions like - how easy consolidated nano/micro ZnO powders will begin to flow or how volume changes as a function of applied normal stress. The first results showed that the slight variations in the shape and size of the $\mathrm{ZnO}$ particles could cause differences in the behaviour of the tested powders.
\end{abstract}

Keywords: ZnO, flowability, angle of internal friction, wall friction, particle size

\section{INTRODUCTION}

Zinc oxide with its unique physical and chemical properties, such as high chemical stability, high electrochemical coupling coefficient, wide range of radiation absorption and high photostability, is currently a widely used material. It is a multifunctional material [1]. The beginnings of the use of $\mathrm{ZnO}$ such as zinc white date back to 1844, as an additive it was used in the vulcanization process of rubber until 1919, it had applications in electronics and optoelectronics also in the early 20th century [2]. With the increasing use of $\mathrm{ZnO}$, the need for its characterization, both physical, chemical and mechanical, also increased. It saw a significant increase in interest with the introduction of nano-ZnO. These are nanorods, -needles, -helix, springs, - rings, - tubes, -belts, -wires, or -combs $[3,4,5]$. Its application possibilities and characterization methods are ever expanding. The size of the $\mathrm{ZnO}$ particles decreases, their specific surface area increases and therefore also the possibility of penetration into organisms and cells. Today, worldwide $\mathrm{ZnO}$ production exceeds one million tons per year and the range of applications is very wide - from rubber, cement, pigments, electronics, sensors, catalytic applications to cosmetics and pharmaceutical additives. Micro-ZnO exhibits a number of different properties compared to nano- $\mathrm{ZnO}[6,7]$. In order handle these powders in a practical way, it is necessary to know their mechanical-physical properties [8]. These include particle size and shape, XRD patterns, shear properties (angle of internal friction and wall friction), bulk properties (compressibility, permeability) or sensitivity of powders to fluidization, so-called aeration. Shear, bulk properties and aeration are influenced, for example, by the amount of air contained, which affects the interaction of particles and therefore also their flow and handling (storage, transport, packaging, process steps) $[9,10]$. Based on the knowledge of the above characteristics, it is possible to modify the process, product formulation, qualitatively compare different production batches, manufacturers or innovate application possibilities, which are currently numerous. The study therefore compares 3 at a glance identical $\mathrm{ZnO}$ powders. For each of them, particle size distribution and the shape of the particles were measured and subsequently the friction parameters, which relate closely to their flow and classification into flow regimes were determined. $\mathrm{ZnO}$ compressibility and permeability appear to be interesting process-determined assays. Compressibility shows how the density of 
powders changes with the applied normal load, and permeability shows how easily air can pass through the powder bed. The seemingly different methodologies are complementary and allow a more detailed analysis of powder behavior. The aeration method then classifies the individual powders into cohesive / typical / noncohesive groups based on the aeration ratio. The paper thus shows not only the possibilities of characterizing nano-, micro- $\mathrm{ZnO}$, but also suggests the interpretation of data in order to predict the process behavior of these very fine powders.

\section{MATERIALS}

For the characterization tests, three white color samples of $\mathrm{ZnO}$ were used (CAS 1314-13-2). These are $\mathrm{ZnO1}$, $\mathrm{ZnO} 3, \mathrm{ZnO6}$ and are shown in Figure 1. The first two are from Bochemie company (www.bochemie.cz/en). $\mathrm{ZnO} 1$ and $\mathrm{ZnO} 3$ are nano-crystalline zinc oxide with high surface area (approximately $100 \mathrm{~m}^{2} \cdot \mathrm{g}^{-1}$ resp. $30 \mathrm{~m}^{2} \cdot \mathrm{g}^{-1}$ ) in powder form. The third one $\mathrm{ZnO6}$ is white powder from Fagron company (cz.fagron.com/en-cz) with quality certificate. It is used as a pharmaceutical active ingredient (API). $\mathrm{ZnO}$ is insoluble in water.
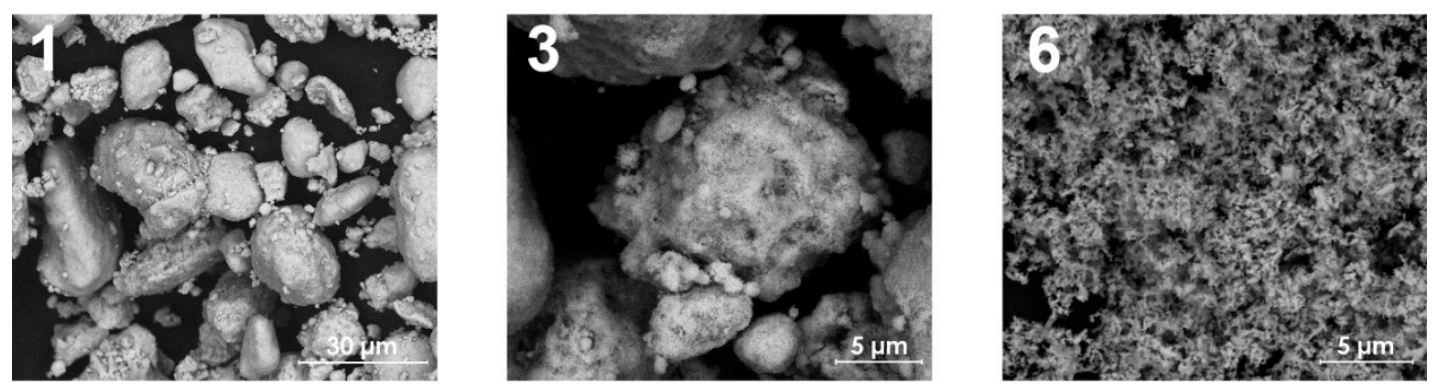

Figure 1 SEM images of $\mathrm{ZnO}$ powders samples

\section{METHODS}

\subsection{Particle size distribution}

The measurement of $\mathrm{ZnO}$ distribution particles was performed on CPS disk Centrifuge RPS 24000. The measurement range is $0.01-40$ microns. This device evaluates the distribution using the centrifugal sedimentation principle. By using several layers of liquid of different density in measure cell is created a transparent measuring space and we call it density gradient. Through this measuring space, the measured particles $\mathrm{ZnO}$ pass and are slowed down by the density difference of the liquid in the gradient layers. Larger particles move faster and small particles move more slowly. This is how sedimentation takes place. The concentration and particle size are detected by a laser. The method of determining the particle size of the sample to the relative weight was used.

\subsection{Aeration, compressibility and permeability}

During the aeration test performed on the Powder Rheometer FT4, the air is brought to the bottom part of the measuring cell while the whole column of the bulk material is aerated. It was observed how much air changes the flow properties of the $\mathrm{ZnO}$ powder by measuring the decreasing amount of flow energy (AE) that was recorded. The range in which flow energy is reduced is, of course, dependent on many physical properties of the powder (e.g. cohesion, particle shape, density). The aeration test was evaluated based on the Aeration Ratio (AR, equation 1) and Aeration Energy (AE) - flow energy during aeration.

Aeration Ratio, $A R=\frac{\text { Energy }(\text { Air Velocity } 0)}{\text { Energy }(\text { Air Velocity } 10)}$ 
Compressibility (or compressibility factor) was measured as the change in volume or density, respectively, depending on a normal load. The data obtained are quantified by expressing the percentage of compressibility for a normal load of 6, 8, 10 and $12 \mathrm{kPa}$. The FT4 Powder Rheometer was used.

Permeability is a measure of how easily material can transmit an air through its bulk. It is influenced by many physical properties such as particle size and distribution, cohesivity, shape, surface texture and bulk density. Consolidation stress are also likely to influence permeability by changing the porosity and particle contact surface areas, making it more difficult for the air to pass through the bulk.

The standard measurement utilises this vented piston to compress the sample under increasing normal stresses whilst at the same time, air is passed up through the vessel at a constant flow rate. Each normal stress is applied for a defined time to allow the powder to reach equilibrium. The air pressure drop across the powder bed is measured for each applied normal stress.

\subsection{Angle of internal friction, wall friction and flowability}

For measurement Angle of internal friction, wall friction and flowability the Brookfield PFT (Powder Flow Tester) was used. This device delivers quick and easy analysis of powder flow behaviour in industrial processing equipment. The device shown in the Figure 2 is used for measuring bulk materials in the range maximum particle size for the Standard Volume Shear Cell is $1 \mathrm{~mm}$, assuming a relatively mono-sized materials and for the Small Volume Shear Cell, the maximum particle size is 250 micron, assuming a mono-sized materials. The principal of operation of the PFT is to drive a compression lid vertically downward into a powder sample contained in an annular shear cell. The annular shear cell is then rotated at a defined speed and the torque resistance of the powder in the shear cell moving against the powder in the stationary lid is measured by a calibrated reaction torque sensor. The geometries of the lid, shear cell, rotational speed of the cell, and the compressive loads applied to the powder all contribute to the calculations which determine the "flowability" of the powder [11]. Jenike flow index ffc is defined $f f c=\sigma 1 / \sigma c$. The relationship between ffc and the flowability - not flowing materials ( $\mathrm{ffc}<1$ ), very cohesive $(\mathrm{ffc}<2)$, cohesive $(<4)$, easy flowing $(<10)$, free flowing $(>10)$ [10].

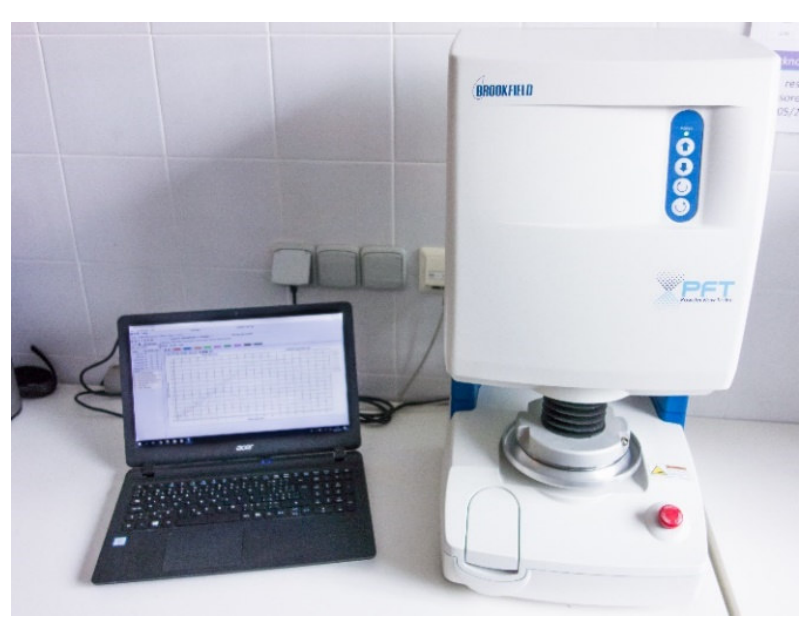

Figure 2 Powder Flow Tester, Brookfield

\section{RESULTS}

\subsection{Particle size distribution}

One of the main parameters influencing the behavior of bulk materials is particle size distribution. ZnO samples were evaluated and fitted in a graph to determine the relative weight and particle size (Figure 2). It can be seen that the largest relative mass fraction of particles is in the range of $550-900 \mathrm{~nm}$ for the ZnO6 sample (50\%). The $900-1500 \mathrm{~nm}$ region of this sample is covered by $16 \%$. The distribution could be referred to as submicron $\mathrm{ZnO}$. For the $\mathrm{ZnO} 3$ sample, the highest relative mass fraction of particles is in the range of 0 $45 \mathrm{~nm}(60 \%)$. Here too, larger particles - 45-200 nm (20\%) and 550-1500 nm (20\%) appear, but in minor amounts. The content of $\mathrm{ZnO}$ nanoparticles dominates. The $\mathrm{ZnO} 1$ sample contains two major fractions in the nano region: $0-45 \mathrm{~nm}(21 \%)$ and $45-122 \mathrm{~nm}(20 \%)$. In this case, the larger particle size may be a cluster of primary particles. 


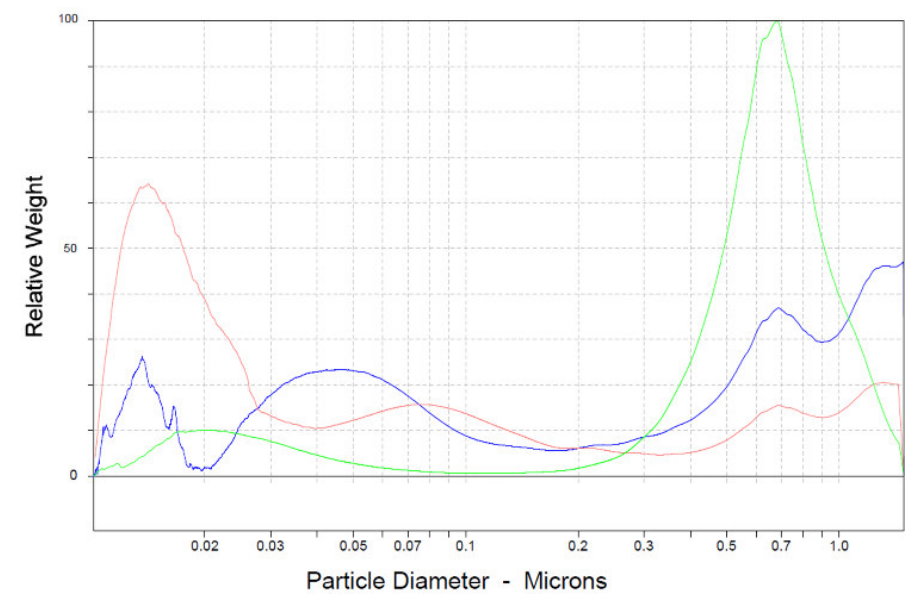

Figure 3 Particle size distribution ( _ $\mathrm{ZnO1}, \ldots \mathrm{ZnO3}, \ldots \mathrm{ZnO6})$

\subsection{Aeration, compressibility and permeability}

Aeration quantifies how the amount of air changes the flow of the test powder. The energy supply values for the aeration of the powder depend on many physical properties, such as cohesion, particle shape, structure and density. From measured data Aerationi ratio and profiles, it is evident (Figure 3) that Zno1 and ZnO3 are categorized as very sensitive to aeration and probably become fluidized. AR values $>>20$. Air is able to pass between each particle and thereby eliminate the effects of mechanical frictional forces and mutual blocking of particles. The results of the $\mathrm{ZnO} 6$ sample show $(2<\mathrm{AR}<20)$ that it is a powder with an average susceptibility to aeration. Most fine powders fall under this regime. The main influence on the flow of powder will remain the interactions between the particles, the air should not significantly break them.

Compressibility is a measure of how the volume changes up to $15 \mathrm{kPa}$ depending on the normal load. For powders, this property is influenced by many factors such as particle distribution and shape, cohesion, particle stiffness, etc. The measured data for the compressibility parameter are shown on Figure 4 (right) and listed in Table 1.
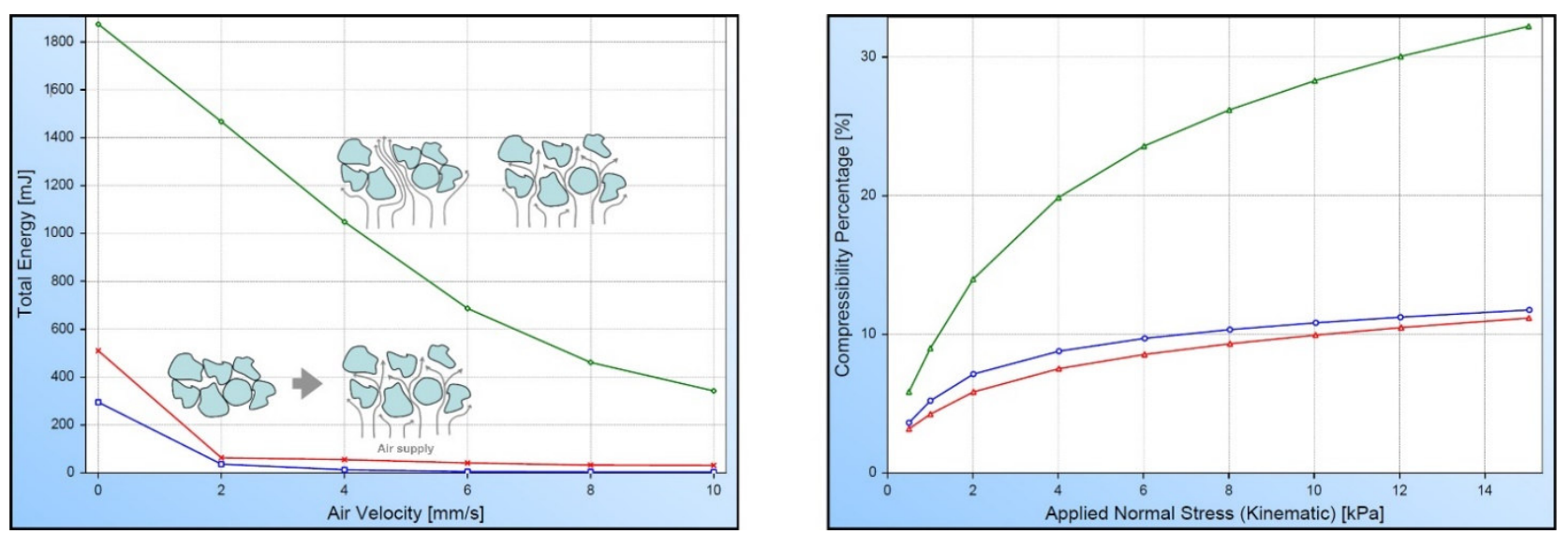

Figure 4 Aeration and compressibility results $\mathrm{ZnO1}$ $\mathrm{ZnO3}$ ZnO6)

Samples of $\mathrm{ZnO} 1$ and $\mathrm{ZnO} 3$ show moderate compressibility according to the results of compressibility factors and depicted dependencies. This is the average susceptibility to compression often associated with slightly cohesive properties of powders. Most fine powders fall into this category. In contrast, the ZnO6 sample shows high compressibility. A high compression factor of $32 \%$ (percentage change in volume after compression) indicates a high air content in the sample and a considerable cohesiveness of the $\mathrm{ZnO} 6$ particles. 
Table 1 Parametry aerace a kompresibility

\begin{tabular}{|c|c|c|c|}
\hline Parameters & $\mathrm{ZnO1}$ & $\mathrm{ZnO3}$ & $\mathrm{ZnO6}$ \\
\hline AR (Aeration Ratio), - & 88.7 & 42.1 & 5.55 \\
\hline $\mathrm{AE}$ (Aeration Energy), $\mathrm{mJ}$ & $3.8 \pm 1.6$ & $31.6 \pm 2.4$ & $342.0 \pm 38$ \\
\hline Compressibility factor (6 kPa), \% & $9.7 \pm 0.5$ & $8.6 \pm 0.3$ & $23.6 \pm 0.6$ \\
\hline Compressibility factor (8 kPa), \% & $10.3 \pm 0.4$ & $9.3 \pm 0.3$ & $26.2 \pm 0.6$ \\
\hline Compressibility factor (10 kPa), \% & $10.8 \pm 0.5$ & $10.0 \pm 0.4$ & $28.3 \pm 0.8$ \\
\hline Compressibility factor (15 kPa), \% & $11.8 \pm 0.6$ & $11.2 \pm 0.3$ & $32.2 \pm 1.5$ \\
\hline
\end{tabular}

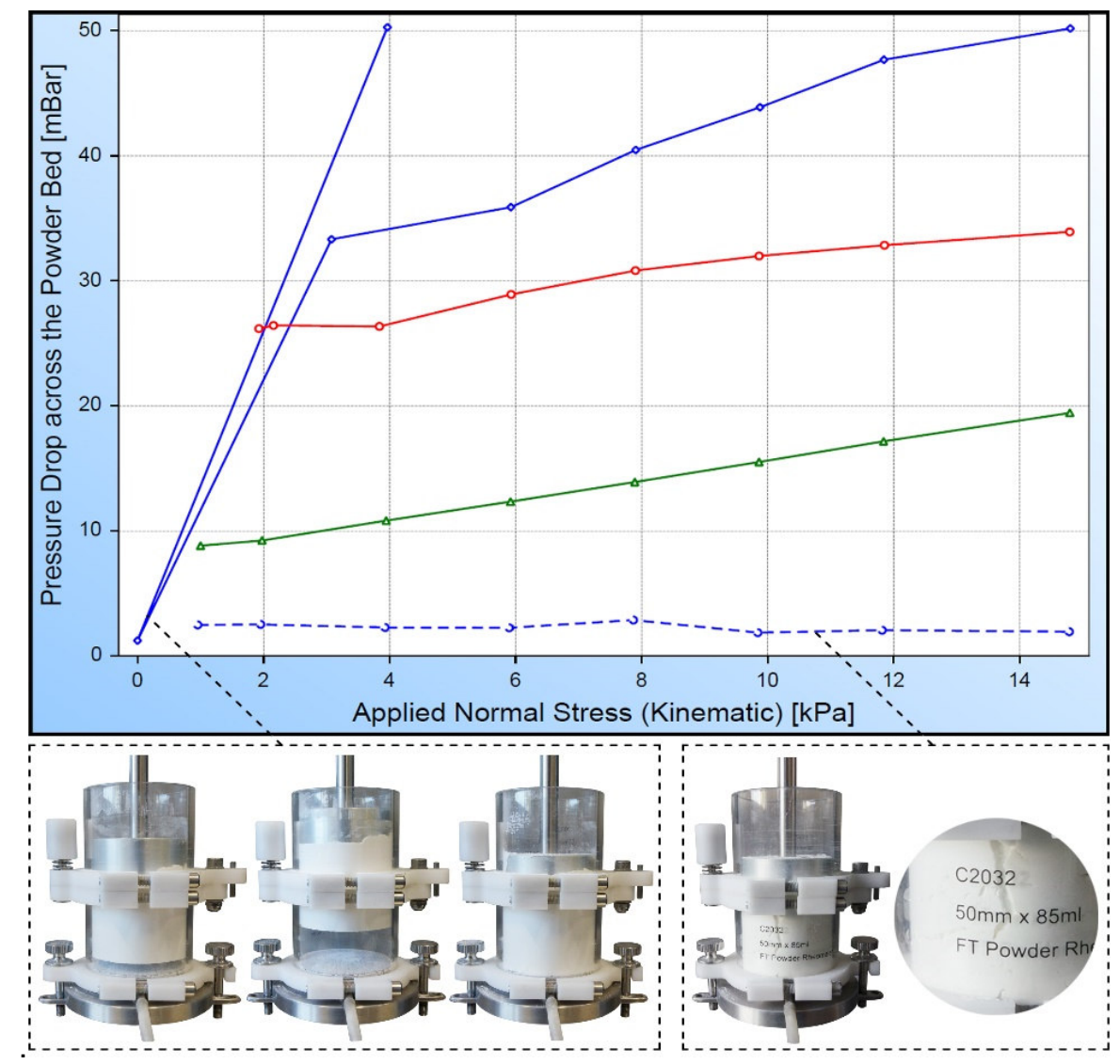

Figure 5 Permeability results $\left(\_\mathrm{ZnO} 1, \ldots \mathrm{ZnO}, \ldots \mathrm{ZnO6}, \ldots \mathrm{ZnO} 1 \mathrm{creating}\right.$ a distorted result due to the air channel). Photos show the measurement description.

The results of the permeability measurements are shown in Figure 5. Determination of air permeability through the powder bed was not easy in the case of the $\mathrm{ZnO} 1$ sample. The air pressure during the first measurement probably exceeded the applied normal voltage. The material was gradually lifted in the measuring cell (Figure Z, photo below left). It then fell completely and the permeability measurement began again from $1 \mathrm{kPa}$. During repeated measurements of the $\mathrm{ZnO} 1$ sample, an air channel was formed at some point and the air pressure decreased (Figure Z, right photo). The pressure drop dependency curve across the powder bed on normal stress was linear with the $x$-axis. The measurement was evaluated as insufficient. In this case, it would probably be appropriate to increase the initial value of the normal stress (i.e. $1 \mathrm{kPa}$ ) to ensure a smooth air permeability through the material. An increase in pressure loss was observed in the $\mathrm{ZnO} 3$ and $\mathrm{Zno} 6$ samples with normal load. Available air passage ducts decreased in size and number during measurement. 


\subsection{Angle of internal friction and flowability, wall friction}

Figure 6 shows flow dependence on internal friction angle. From the graph it is evident that the samples $\mathrm{ZnO} 1$ and $\mathrm{ZnO} 3$ are in a different flow regime than sample $\mathrm{ZnO6}$. This is in line with previous measured data. Samples $\mathrm{ZnO} 1$ and $\mathrm{ZnO} 3$ belong to the cohesive material class according to ffc, sample $\mathrm{ZnO} 6$ belongs to the very cohesive material class. The procedural handling of such fine cohesive materials should be modified on the basis of this information.

The results of the external friction of the $\mathrm{ZnO}$ powders are shown in Figure 7. Previous data is supported. External friction has, for stainless steel contact materials, the highest value for the $\mathrm{ZnO6}$ sample, due to significant cohesive forces. The external friction for the $\mathrm{ZnO} 1$ and $\mathrm{ZnO} 3$ samples is not very different. The same equipment can be used for transport handling.

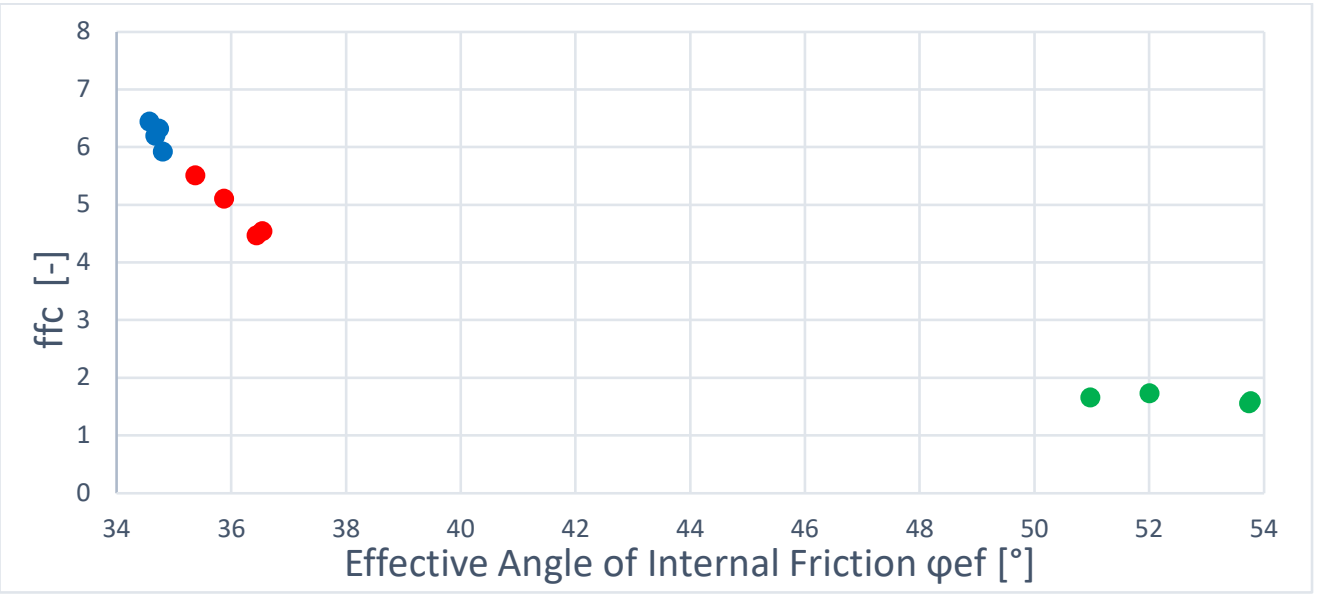

Figure 6 Dependence ffc on effective angle of internal friction ( $\mathrm{ZnO1}, \mathrm{ZnO},, \mathrm{ZnO6})$

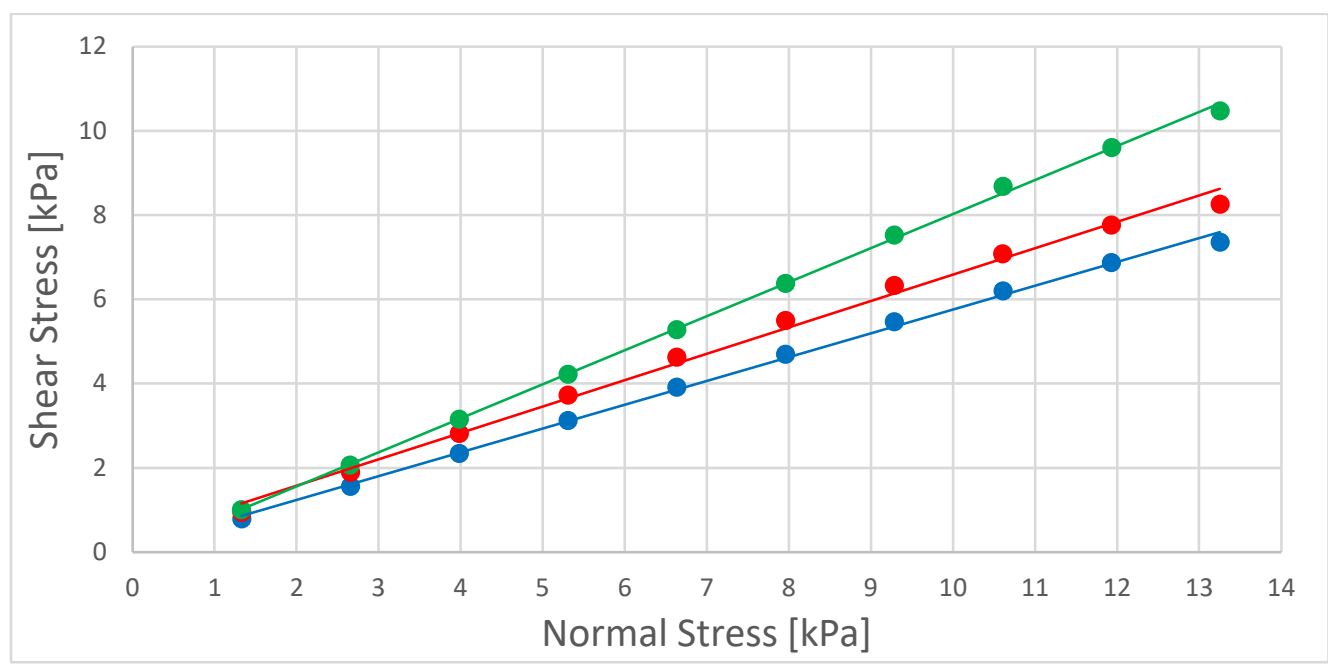

Figure 7 External friction $(, \mathrm{ZnO} 1, . \mathrm{ZnO},, \mathrm{ZnO6})$

\section{CONCLUSION}

The paper shows some possibilities of characterization of powdered nano-, micro- ZnO. Three different samples were selected (Bochemie, Fagron). SEM photographs pointed to a different shape and structure of particles of the at first glance identicle powders. Considering the measured distribution curves, it could have been assumed that the $\mathrm{ZnO} 1$ and $\mathrm{ZnO} 3$ sample were cohesive and their flowability and process manipulation 
with them will be difficult.. However, a more detailed characterization did not confirm the hypothesis. From the aeration results it was found that fine $\mathrm{ZnO} 1$ particles (separated, rather round shapes) fall into the aeration group of rather non-cohesive powders. Air flows around each particle separately. The compatibility was moderate.

The $\mathrm{ZnO} 6$ sample (as opposed to the $\mathrm{ZnO} 1$ and 3 samples) was closer to a cohesive powder based on the measured compressibility values. The $\mathrm{ZnO} 6$ sample contains very small primary particles that cluster into a "network". Air flows around clusters during aeration, compression is significant. The conclusion that the $\mathrm{ZnO} 6$ sample is cohesive was also confirmed by the measurement of external, internal friction, and flow. An interesting finding was the determination of sample permeability. The $\mathrm{ZnO} 1$ sample started lifting and air channels began forming due to very low air pressure. From a process point of view, this information concerns the flow of powder from a dispenser where vaulting, pneumatic conveying or a fluidized bed drying may occur.

\section{ACKNOWLEDGEMENTS}

\section{This paper was conducted within the framework of the project L01404: Sustainable development of ENET Centre, by the student grand competition SP2019/115: Research in optimized design of transport and storage processes using test equipment and simulation techniques and Faculty of Mechanical Engineering.}

\section{REFERENCES}

[1] SEGETS, D., GRADL, J., TAYLOR, R.K., VASSILEV, V., PEUKERT, W. Analysis of optical absorbance spectra for the determination of $\mathrm{ZnO}$ nanoparticle size distribution, solubility, and surface energy. ACS Nano, 2009. vol. 3, pp. 1703-1710.

[2] KLINGSHIRN C., FALLERT J., YHOU H., SARTOR J., THIELE C., MAIER-FLAIG F., SCHENIDER D., KALT H. 65 years of $\mathrm{ZnO}$ research - old and very recent results. Phys.Status Solidi B, 2010. vol. 247, No. 6, pp. 14241447.

[3] BANERJEE, D., LAO, J., WANG, D., HUANG, J., REN, Z., STEEVES, D., KIMBALL, B., SENNETT, M. Largequantity free-standing ZnO nanowires. Appl. Phys. Lett, 2003. vol. 83, pp.2061-2063.

[4] WAHAB, R.; ANSARI, S., KIM, Y., SEO, H.; SHIN, H. Room temperature synthesis of needle-shaped ZnO nanorods via sonochemical method. Appl. Surf. Sci, 2007. vol. 253, pp. 7622-7626.

[5] NIKOOBAKHT, B.; WANG, X.; HERZING, A.; SHI, J. Scable synthesis and device integration of self-registered one-dimensional zinc oxide nanostructures and related materials. Chem. Soc. Rev, 2013. vol. 42, pp. 342-365.

[6] KAPTAY G.: On the size and shape dependence of the solubility of nano-particles in solutions. Int J Pharm, 2012. vol. 430, pp. 253-257.

[7] YANG, Chun, Ch., YIU-WING M.: Thermodynamics at the nanoscale: A new approach to the investigation of unique physicochemical properties of nanomaterials. Mat Sci Eng R, 2014. vol. 79, pp. 1-40.

[8] LETURIA M., BENALI M., LAGARDE S., RONGA I., SALEH K.: Characterization of flow properties of coehsive powders: A comparative study of traditional and new testing methods. Powder Technol, 2014. vol. 253, pp. 406423.

[9] FREEMAN Reg, E., COOKE James, R., SCHNEIDER Louis C.R.: Measuring shear properties and normal stresses generated within a rotational shear cell for consolidated and non-consolidated powders. Powder Technol, 2009. vol. 190, pp. 65-69.

[10] Zheng, Y., Lu, H., Guo, X., Gong, G.: Study on the effect of nanoparticles on the bulk and flow properties of granular systems. Fuel Process Technol, 2018. vol. 177 pp. 30-38.

[11] AMETEK BROOKFIELD LIBRARY. Brookfield Powder Flow Tester: Operating Instructions, manual, No. M091200-F1016 [online]. Version 1, Last updated: 08. August.2017. Middleboro: AMETEK Brookfield. 76 p. [viewed 2019-07-24]. Available from: https://www.brookfieldengineering.com//media/ametekbrookfield/manuals/pft/updated\%20pft\%20m09-1200-f1016.pdf?la=en 